\title{
On the Current Situation and Improvement Measures to English Teaching in Private Universities
}

\author{
Ai Xizhen, Xiong Cailan \\ Nanchang Institute of Science \& Technology, Nanchang 330108, China
}

\begin{abstract}
Improving the quality of teaching is the sacred duty of leading cadres at all levels in private universities. Therefore, teaching is the central work of private universities, teaching management has become the center of the management of private universities. Private universities have made great progress in English teaching, we must also clearly realize that there are many problems in the English teaching in private universities. Therefore, through extensive research and teaching practice, reflect the status quo of private universities English teaching, analyzes a series of problems, show reasons for restricting the effect of English teaching, and on this basis, put forward the corresponding countermeasures.
\end{abstract}

Keywords: Private Universities; Teaching Reform; Measures

\section{Introduction}

In recent years, the national college English teaching from a basic English skill, or focus on the description of new teaching mode, multimedia technology and autonomous learning under the network environment, or in a cross cultural perspective as a starting point to discuss the reform of College English teaching. From the literature survey, the majority of college English Teaching Reform for the teachers themselves, but from the perspective of college students are relatively small, the real needs of college students should cause people's attention. As for the current situation of college English teaching, some scholars, such as Ma Xiaomei, have studied the motivation and interest of students of science and engineering by grade, such as, from the perspective of college English teaching and learning, such as the reform of college English teaching from the perspective 
of college English teaching and learning an investigation into the current situation of college English classroom teaching from the perspective of the combination of leather and middle school English. As one of the national higher education personnel training bases, private higher education institutions should take the responsibility of cultivating high-level English talents. With the deepening of education reform, private colleges has made great progress in English teaching, the teachers level is greatly improved, the teaching management is increasingly perfect, students pay more attention to the English level is also increased. They are required to improve their English listening, speaking, reading, writing and translating ability. The students of private universities are particularly weak in English ability, and the English education in private colleges is facing unprecedented challenges. How to improve the level of English teaching as soon as possible, private universities for a unique group of students, should take what kind of road, what kind of characteristics to meet the needs of society has become a priority.

\section{The current situation and problems of English teaching in private universities}

Through the research, access to relevant information and teaching observation, we found that the problems in English Teaching in private universities are mainly based on several situations:

As the private universities do not have government finance as the support, it is under great pressure to survive. In view of these reasons, private college admission scores lower than undergraduate college admission standards, so the overall level of the quality of students is low, student enrollment scores especially poor grades in English, English foundation is weak. Private universities due to the lack of capital, audio-visual equipment are aging, backward and frequent faults. English teachers still use tape recorders for students to listen in the class, the recorder is also very normal function, many teachers have to bring their own equipment to maintain normal teaching. The number of multimedia classroom is relatively small, can not meet all the teaching requirements. Some of the data should be displayed with multimedia, pictures can not be displayed to the students, the students can not intuitively understand some of the knowledge, teachers can only use language to convey, and thus greatly reduce the effectiveness of teaching. Even if there is a multimedia classroom, the computer is also need to update in urgent.

Professor Zhu Zhixian, a psychologist in our country, stated in the report of "the ideal, motivation and interest of the National Youth" that in some of the subjects, the students do not like English. This phenomenon is particularly prominent in the relatively weak private university students. After the high school learning stage, after entering the university campus, as a result of the university study by self-study, self management, students do not like to stay in their parents around, subject to discipline and restrictions. Learning and the lack of 
supervision of the teacher and parents, unlike in the past work, a lot of people holding mixed diploma mentality for the exam is also very indifferent attitude, the results also hold not only for high clearance psychology.

In the aspect of English learning, the requirement of College Students' listening and speaking ability is that college students should correctly understand the standard target language (i.e. English) and understand the pronunciation rules of the target language. Imitation of the target language, that is, the standard English. It can be seen that the current education system is more and more emphasis on training students' practical ability in English application. However, in contrast to the quality of college students in private colleges, we can see that due to the constraints of the examination oriented education system, students in primary and secondary education is only to teach them how to do a good paper. Thus, there is no basis for the formation of some English accurate, solid grasp. Therefore, for a weak foundation of students, because of hearing transient features plus their pronunciation is not standard, lack of knowledge, small vocabulary speech and other factors, listening is more difficult. For the better students, although the hearing is better, but due to the lack of spoken English training, spoken language ability is weak.

Private universities in the English teaching process, measure students in the English test pass rate to the learning situation of students and teachers teaching quality. Therefore, teachers in the teaching process, often followed the examination oriented education blindly echo what the books say indoctrination, the sea tactical plant which is the main factors leading to students' interest in English is not high, the plant capacity is not strong. Oral English should be taught in small classes so as to ensure that every student has the opportunity to practice oral English. But private universities arrange the number of the numerous students in the same class, class teaching to practice oral English is very difficult, time-consuming and laborious. And most of the students in the early, high school is just busy with the sea tactics of the exam oriented education, did not practice spoken English, basic English language ability is poor. They can't understand even the most basic and simplest spoken English, which undoubtedly brings obstacles to English teaching. Due to poor English foundation, learning is not hard enough, every year to apply for CET4/ 6, and pass through. Some people even have a chance to get out of the house, and buy the answer, looking for gunmen, equipped with advanced cheating tools, no need not its pole. We can imagine that ET4/ 6 pass rate can not be high.

\section{Improvement measures}

The introduction of a new teaching model, to stimulate the deep motivation of learning, focusing on the ability to develop generally think that learning motivation sub surface and deep. Surface motivation comes from outside, such as learners' motivation for the future needs of the individual, and deep motivation comes from the interest of English language and culture itself. Different motives lead to different interests, learning attitudes and learning persistence, which will 
affect the final effect of learning. The deeper the motivation is, the stronger the desire to use information about the target language and the culture it contains, and the more autonomous, the better the effect of learning. Therefore, it is the key to stimulate the interest of the students to develop and improve the deep motivation of English learning in foreign language teaching. The motivation of learning deep motivation is not realized by the existing teaching mode. Therefore, private universities must introduce a new teaching model to focus on the cultivation of English ability.

In view of the uneven level of students, the school can be divided into different levels of students, teaching at different levels. For a weak foundation of students can be appropriate to slow down the speed increase of class teaching, and strengthen the first, focus on strengthening its basic grasp of English; on the basis of good students, in the textbook content specified, should expand their knowledge of language and culture, to cultivate and improve the overall quality of the English.

We can't take the monotonous method and the teacher centered teaching mode. At present, the reform direction of English teaching is to establish a students-centered classroom teaching mode, which is also the practice of language teaching. As Hame says, the best teachers are those who think about what they should do in class and how to organize them. Moreover, the new role of teachers includes helpers, facilitators, mentors and guides. In addition, the classroom time is limited, so the guidance, training, encourage students to extracurricular self-study is very necessary, Because extracurricular learning is very important to improve English learning ability.

Teachers should pay more attention to the role of emotional education in English teaching process. The ancients said: a student will believe in teaching only when he gets close to his teachers. Teachers should use "love" to win the trust and close to students, teachers and students make mutual communication of feelings, close the relationship between teachers and students, the formation of a relaxed and pleasant atmosphere in the classroom. In view of this, teachers should strengthen communication with students. Therefore, in the classroom teaching process, we should adopt a positive incentive mechanism, which is encouraging and positive. After class teachers should also strengthen communication with students, so that they feel that the teacher is like them, each of them has its own advantages, it is possible to learn lessons through hard work. To give more encouragement and praise, positive motivation is an effective motivation for students to actively.

Make full use of multimedia production, financial knowledge, sound and animation picture in one of the teaching courseware, and screening of knowledge and culture, is conducive to the growth of knowledge and language learning disc. This kind of sound, image and text as one of the teaching methods for students to create immerse English learning atmosphere, students will naturally increase the interest in learning. According to the survey, 55\% of respondents preferred to discuss the theme around the DVD or VCD segment with a sound image.

Teachers should create language practice opportunities for students as much as possible from class to class. Such as: the organization of language games, open 
competition, English corner, English interest groups, rehearse English entertainment programs on teachers and students to ask the students asked in English greetings, ask students to use English in daily life to stimulate students' curiosity and interest in learning. If you have the conditions, you can not regularly invite foreign teachers to do lectures and exchanges, in order to enrich the content of the classroom, which is the subject of the call.

\section{Conclusion}

As a special group of higher education institutions, private universities have spared no effort to contribute their strength. But the most urgent task in English teaching is to develop the second classroom. This is mainly manifested in the following aspects: first, it can create a good atmosphere for students to learn English and create a good environment for language learning. Because the second classroom activity is the students' voluntary participation, it is easy to convert the passive learning into the conscious learning, which is helpful for the students to learn actively. Second is to improve students' practical ability in English. The second classroom activities, students in a real language environment, the knowledge will be used to understand and digest memory, second classroom activities, extensive contents, various forms of let students get language training opportunities. Third is to promote college English classroom teaching. In the classroom, the students tend to learn more about the English language skills and the comprehensive ability to use English. The second classroom activities to create a good English learning environment, conducive to the development of students' personality, cultivate their ability to use English, the classroom teaching and extracurricular teaching organically, consolidate college English classroom teaching effect, is real beneficial to college English teaching.

Schools and colleges should actively cooperate with each other to create a lively atmosphere of good language learning, which is the subject of the general voice and recommendations. Only by the joint efforts of all parties, the whole school English teaching and the improvement of students' English quality will achieve the best results. In China's higher education in the process of development from elite education to mass education, sustainable, harmonious and all-round development of private universities must focus on students, adhere to the student oriented, and actively build financial education, management, service and development for the development of work mode. Hope this research can serve as a useful reference.

\section{References:}

[1] Xiujie L I. Current Situation and Improving Method of Teaching and Learning of College English Translation[J]. Cross-Cultural Communication, 2007, 3(2). 
[2] Zhang Z J. Analysis and Research on the Current Situation of College English Translation Teaching[J]. Journal of Chongqing University of Technology, 2013.

[3] Fang F. On the Current Situation and Improvement of Reading Comprehension Teaching for English-majors in universities[J]. Science Education Article Collects, 2014.

[4] Chen B. On the Current Situation and Improvement Measure of Translation Teaching for English Majors[J]. Overseas English, 2016.

[5] Xia G, University E L. Analyses on Present Situation of College English Translation Teaching and Improvement Strategies[J]. Journal of Hubei Correspondence University, 2016. 